The University of Southern Mississippi

The Aquila Digital Community

Faculty Publications

$10-1-2010$

\title{
African American Ethnic and Class-Based Identities on the World Wide Web: Moderating the Effects of Self-Perceived Information Seeking/Finding and Web Self-Efficacy
}

\author{
Jennifer R. Warren \\ Rutgers University \\ Michael L. Hecht \\ Pennsylvania State University, mlh10@psu.edu \\ Eura Jung \\ University of Southern Mississippi, Eura.Jung@usm.edu \\ Lynette Kvasny \\ Pennsylvania State University \\ Mark G. Henderson \\ Jackson State University, mark.g.henderson@jsums.edu
}

Follow this and additional works at: https://aquila.usm.edu/fac_pubs

Part of the Communication Technology and New Media Commons

\section{Recommended Citation}

Warren, J. R., Hecht, M. L., Jung, E., Kvasny, L., Henderson, M. G. (2010). African American Ethnic and Class-Based Identities on the World Wide Web: Moderating the Effects of Self-Perceived Information Seeking/Finding and Web Self-Efficacy. Communication Research, 37(5), 674-702.

Available at: https://aquila.usm.edu/fac_pubs/880

This Article is brought to you for free and open access by The Aquila Digital Community. It has been accepted for inclusion in Faculty Publications by an authorized administrator of The Aquila Digital Community. For more information, please contact Joshua.Cromwell@usm.edu. 
Running head: ETHNIC AND CLASS-BASED IDENTITIES ON THE WWW

African American Ethnic and Class-Based Identities on the World Wide Web:

Moderating the Effects of Self-Perceived Information Seeking/Finding and Web Self-Efficacy

\author{
Jennifer R. Warren \\ Michael L. Hecht \\ Eura Jung \\ Lynette Kvasny \\ Mark G. Henderson
}

Jennifer R. Warren (corresponding author) is a postdoctoral associate in the Program for Health Disparities Research, Medical School, at the University of Minnesota, jrw@,umn.edu, 612-6268798.

Michael L. Hecht is a Distinguished Professor of Communication Arts and Sciences at the Pennsylvania State University, mhecht@psu.edu, 814-863-3545.

Eura Jung is an Assistant Professor of Speech Communication at the University of Southern Mississippi, eura.jung@usm.edu, 601-266-4276.

Lynette Kvasny is an Assistant Professor of Information Sciences and Technology at the Pennsylvania State University, 1kvasny@,ist.psu.edu, 814-865-6458.

Mark G. Henderson is the Director of Theatre and Assistant Professor of Speech Communications at Jackson State University, mark.g.henderson@ccaix.jsums.edu, 601-9688612 


\begin{abstract}
The web is a potentially powerful tool for communicating information to diverse audiences. Unfortunately, all groups are not equally represented on the web, and this may have implications for online information seeking. This study investigated the role of class- and ethnic-based identity in self-perceived web-based information seeking/finding and self-efficacy. A questionnaire was administered asking African Americans about their class and ethnic identities and web use to test a conceptual model predicting that these identities are positively related to web-based information seeking and web self-efficacy, which are then positively related to webbased information finding. Gender and previous web experience were expected to moderate the relationships. Structural equations modeling of these data support most of the predictions and indicate that these identities influence perceptions of online information seeking.
\end{abstract}




\section{Introduction}

A critical challenge facing human society is how to realize the democratizing potential of the internet in an era when its user-base is rapidly expanding and diversifying (Bucy, 2000). According to Haythornthwaite (2007) an emerging area of study focuses upon online content to explain the use and non-use of web-based information. Despite growing use of the web by nonmainstream groups and evidence that the effectiveness of web-based messages depends at least to some extent on their relevance to various identities (Appiah, 2004; Kalyanaraman \& Sundar, 2006), many parts of the web still under-represent and/or distort nondominant group identities (Gibbons, 2005; Kvasny \& Warren, 2006; Ndiaye, Krieger, Warren, Hecht, \& Okuyemi, 2008). Although Americans of color are overrepresented on many sports and popular music websites (Nakamura, 2004), there is a paucity of other web-based content and resources (e.g., health information, financial resources) representing or including ethnic (i.e., cultural) and low-income identities of adult Americans (Haythornthwaite, 2007; Jackson, et al., 2002; Lazarus, Lipper, Roberts, Fireman, \& Rose 2003; Norris \& Conceicão, 2004; Stanley, 2003). Relevant content such as local cultural/community interests and ethnically appropriate health resources (Detlefsen, 2004; Gibbons, 2008; Katz \& Rice, 2002; Lazarus, et al., 2003) is not only limited, but available websites often treat ethnicity and other non-mainstream identities in a reductive manner (e.g., pictures of African Americans on a site with general information for African American users) (Kvasny \& Warren, 2006). Moreover, research has noted an ethnic and class bias inherent in the design of the web (e.g., interfaces, portals, information) (Hecht, Warren, Jung, \& Krieger, 2005; Jackson, et al., 2002; Kolko, 2000).

This scenario is problematic for under-represented groups such as African Americans whose internet use is increasing. In a 2007 national survey, 62\% of African Americans are now 
online, a 36\% increase from 2000 (Pew and Internet Life, 2007). Surveys in 88 US markets also revealed that African Americans spent an average of 117 minutes per day online in 2007 (17\% of their typical media day), up from 68 minutes in 2006 (Media Audit's, 2007). African Americans actively surf the web to seek job opportunities, civic and interpersonal interaction, health information, and entertainment (Gibbons, 2005; Mehra, Merkel, \& Bishop, 2004; Nakamura, 2004). So, while African American's internet usage is increasing, there remains a lack of content directed toward their needs. This disadvantages African Americans because, in general, people respond more favorably to information sources that reflect their identities (Airhihenbuwa, 1995; Selwyn, 2003).

Given the growth in internet uptake by African Americans and the limitations of the content that represents this group, there is a need for studies that examine their perspective on web use and online information. This study employs an approach grounded in the dual consciousness of African American self and recent theorizing suggesting that identity plays a role in information seeking, including searches conducted online through the web (Hecht et al., 2005). It is natural that one's notion of self is implicated in information seeking; who we are (e.g., researcher, doctor, mother) often influences what interests us and drives the key processes of searching, finding, assessing, interpreting, and using/interacting with information (Warren, Allen, Okuyemi, Kvasny, \& Hecht, 2009).

Group-based identities are particularly salient. In general, communication that adjusts to and accommodates cultural identities is more effective (Airhihenbuwa, 1995; Selwyn, 2003; Shepard, Giles, \& Le Poire, 2001) and online communication is no different. Research has noted the importance of ethnicity in determining the effectiveness of mediated information for users and judgments of the relevance and utility of web-based information are related to the degree to 
which ethnicity is communicated through qualities such as graphics and text (Appiah, 2004). In addition, identity-relevant information fosters confidence in utilizing information (Airhihenbuwa, 1995). It appears, then, that having access to identity-relevant information has important implications for nondominant group members' confidence in being able to seek, find, and interact with web-based information.

As a result, this study examined how perceived group identities based on social class and ethnicity influence self-perceived information seeking and self-efficacy in using the web among African Americans who seek information through mainstream search engines (e.g., Google) and ethnic-based web portals (e.g., BlackAmericaWeb). What follows is an explication of the theoretical framework, review of relevant literature, the guiding hypotheses, methods, results, and discussion. We begin our discussion by presenting a theoretical frame for identity.

Theoretical Framework

\section{Communication Theory of Identity}

Like the web itself, identity is multi-layered. Both require a complex and fluid framework. As a result, we chose the Communication Theory of Identity (CTI) to guide our inquiry. Among the various layers or frames of identity described by the theory, CTI argues that group-based personal identities and communal identities are important constructs in an individual's understanding of who they are as well as society's constructions of groups (Hecht, 1993; Hecht, Jackson, \& Ribeau, 2003; Hecht et al., 2005). Group-based personal identities are ways individuals define themselves or their self-concept based on associations with social groupings that offer resources for self-categorization and social comparison (Tajfel \& Turner, 1986). Communal identities are qualities of the collectivity communicated by cultural products such as television shows and websites (Hecht et al., 2003). CTI conceptualizes these and other 
types of identity as motivational sources that structure expectations and behaviors. Thus, both of these frames of identity are likely to influence online information seeking.

The CTI approach to group-based identity emerged within the tradition of Social Identity Theory, which notes that people come to know themselves through a process of selfcategorization and social comparison (Tajfel \& Turner, 1986). The cohesion of a social group with which individuals identify is based upon held-in-common beliefs, values, behavioral norms, speech styles, and other perceived relevant characteristics. Individuals are viewed as outsiders when they do not reflect the held-in-common characteristics of the group or neglect to provide appropriate cues or some other indication that they indeed are a member. Also, people are categorized by others as belonging to social groups based on many factors such as skin color, economic status, and cultural traditions. Individuals often will have favorable biases toward social groups with which they identify, viewing more positively cues signifying those group memberships (Hewstone, Rubin, \& Willis, 2002). These biases may arise without much thought (Hewstone et al., 2002).

Regardless of whether one chooses to identify with a particular group or is assigned to a group by others, CTI argues that group-based identities are communicatively performed, confirmed, invalidated, or ignored in social interaction (Hecht et al., 2005; Hogg, 1993; Jackson et al., 2004). The meanings ascribed to these identities are communicated in behaviors that can include information seeking; both the type of information sought as well as where one goes to find it (Warren, Kvasny, Hecht, Ahluwalia, \& Okuyemi, 2009). This has implications for the presentations of identities; a phenomenon CTI labels communal identities.

Communal identities represent a different level of analysis - the identities represented by the collectivity or community. The communal identities presented online tend to over-represent 
dominant identities and misrepresent or distort non-dominant identities that can give rise to perceptions of the internet as a tool for dominant groups within the United States (Kvasny, 2006). This has led some to conclude that members of non-dominant identity groups, such as African Americans, may not find particular types of web-based information useful (Gibbons, 2008; Haythornthwaite, 2007; Jackson et al., 2002; Stanely, 2003; Warren, Allen, et al., 2009). Conversely, members of identity groups such as African Americans may be motivated to use websites that reflect held-in-common communal identities or, perhaps, to avoid the internet if it is perceived to exclude or misrepresent these identities.

Thus, both group-based and communal identities are likely to influence online information seeking. Using the CTI as our theoretical framework, we predicted that group-based ethnic and class identities would influence self-perceived web-based information seeking behavior due to representations of communal identities in web-based information. Group-based identities are likely to influence seeking and finding online information, choosing certain websites and avoiding others based on communal identity representations (Hecht et al., 2005). Next, we summarize what is known from previous research about the relationships among groupbased and communal identities on online information seeking.

\section{Group-Based/Communal Identities in Perceived Web-Based Information Seeking}

The information seeking literature (Agada, 1999; Anwar, Majid, \& Eisenschitz, 2000; Baker 1996; Jeong, 2004; Spink \& Cole, 2001) suggests that group-based and communal identities influence information seeking and finding. For instance, Anwar et al. (2000) found that among agricultural scientists in Malaysia, information needs and behaviors related to the seeking and selection of information were based on common characteristics and understandings across this community of scientists. Jeong (2004) noted that due to a strong group-based identity, 
Korean students tend to seek information from individuals of their own ethnic group who represent held-in-common experiences and understandings. Lower income African Americans seek information from within their own subculture and use gatekeepers as intermediaries between the subculture and the information resources of larger society (Agada, 1999). Spink and Cole (2001) report that people in low income homes tend to seek information through informal channels (e.g., family, friends) and marginalize more formal channels (i.e., internet) to obtain information.

In general, people seem to be motivated by information sources from their own cultural groups or from sources including representations of their communal identities (Hecht \& Krieger, 2006). This research suggests that both the group-based identities of users and the representation of communal identities in information sources play key roles in online information seeking behaviors. While use of the internet is often very purposive, focused, and goal directed (e.g., we look to buy a certain product or for specific news events), we still expect that the information will be more useful if it is reflective of communal identity. However, few studies have been conducted to explicitly test assumptions about the role of group-based and communal identities in perceptions of seeking and finding information on the web.

\section{Challenges in Access}

Historically, much of the research on group-based and communal identities and internet use has focused on gaps in access to technology (e.g., the digital divide). While there is still unequal online participation across diverse groups, this approach fails to consider the increasing participation by non-dominant groups, such as African Americans (Pew Internet and American Life, 2007). Research points out several areas that impact the use of the web including skill levels (van Dijk \& Hacker, 2003), social constraints/supports (Barzilai-Nahon, Rafaeli, \& 
Ahituv, 2004), motives, self-confidence, as well as ethnic, cultural and identity-related factors; Jackson, Ervin, Gardner, \& Schmitt, 2001b; Stanley, 2003). For instance, ethnicity and identity are highly correlated with reasons why people choose to use the internet, such that in one study African Americans did not perceive computers as relevant to their lives or as part of their self concept (Stanley, 2003). Moreover there remains a lack of culturally (or communally) relevant information on the web (Haythornthwaite, 2007), suggesting a need to further identify cultural factors that impact the architect of the internet itself, the design of web-pages, and internet use (Jackson, et al., 2002).

In line with this research, issues of access to technology also include disparities in access to relevant information online, especially among those who were historically believed not to have computers. Information-rich individuals and communities have access to sources of information relevant to who they are that allow them to anticipate events and make informed decisions (Jameson \& Sligo, 2000). This means that the nature of the information available online creates differences in this new type of access. Therefore, it is important to focus efforts on a potentially important influence on computer use: the paucity of web-based information relevant to the interests of nondominant groups (Brock, 2006).

Our reasoning derived from CTI leads us to argue that group-based identities and the online representations of communal identities have ramifications for people's belief in their ability to seek information online (Jackson et al., 2001b) and, thus, influence self-perceived webbased information seeking and finding. In other words, some groups are privileged because the information is targeted to their identity groups, making the information more salient and more accessible to them. Identities such as social class and ethnicity are likely to be particularly salient since they play a key role in access issues. 


\section{Ethnic Identity and the Web}

The influence of ethnic identity on information seeking has been studied widely. Strong ethnic identity plays a role in channel consumption (Desphande, Hoyer, \& Donthu, 1986; Donthu \& Cherian, 1992). Appiah's $(2003,2004)$ web-based research indicated that people choose what messages to attend to based on perceived similarities between themselves and the source. People tend to feel gratified by media use through its relation to their experience and information needs (Means-Coleman, 1998).

As a result, important ethnic differences have been found in attitudes toward the use of web-based content. The Cultural Access Group (2001) found that more than half (52\%) of African American respondents said people of color have unique web-based needs, compared to only $16 \%$ of the general market. Moreover, only $33 \%$ of African Americans said content on the web is adequate for them. Thus, identity representation appear to be particularly salient to African Americans and, along with the access trends noted previously, led us to focus this paper on African Americans and their use of the web.

Like other identity groups, there are some African American audience members who most strongly identify with African American characters and prefer media channels delivering information with which they can identify (Appiah, 2004; Nakamura, 2004). According to Nakamura (2004), because popular music and sports features people of color quite regularly as performers and players, American ethnic minorities may prefer to view websites that provide these images of ethnic-based identity for entertainment purposes. In addition, many African Americans utilize the web for other leisure purposes, such as chatting and instant messaging.

On the other hand, websites with information geared toward a more mainstream audience may not yield the same effect for some African American users who, without seeing relevant 
communal identities represented, may be discouraged from searching for further information on the website and perhaps the web in general (Warren, Allen, et al., 2009; Warren, Kvasny, et al., 2009). Appiah's (2003) research which has utilized various ethnic cues (i.e., pictures of African Americans, the term Black) on websites, found that African Americans tend to spend more time browsing websites that target African American than those sites targeting White users. The preference for information targeting ethnic identity on a particular website may affect web-based searching, especially if the information they are finding does not reflect appropriate ethnic cues.

\section{Class-Based Identity and the Web}

Similar to ethnicity, social class differentiates individuals' experiences, practices, and how they perceive the world (Aries \& Sieder, 2005; Bottero, 2004). Many factors contribute to these disparities, including the distribution of resources, life chances, and perceptions of one's abilities (Aries \& Sieder, 2005). Class-based identity becomes salient as individuals perceive themselves or are grouped as similar by others based upon factors influencing social class position (Bottero, 2004; Durant \& Sparrow, 1997). Commonly valued social and cultural practices, such as private home ownership and living in 'the suburbs' have been representative of a middle class identity. Thus, lifestyle choices and tastes (Bottero, 2004) and access to resources/information (Bolam, Murph, \& Gleeson, 2004) can suggest a class-based identity and vice versa.

Rarely, has class-based identity been examined as an influence on web-based information seeking. Historically, it has been assumed that economically-challenged groups have limited access to technology and low levels of technology literacy. Even as technology becomes more readily available to these groups, education (one of the key dimensions of social class status) remains strongly related to internet use. Individuals with a college degree are more likely to have 
a computer and access to the internet than individuals with less education (Kalichman et al., 2002). As with ethnicity, these disparities also are reflected in web-based content, with few online resources targeting adults in low income groups through which they could search and be able to locate relevant information (Gibbons, 2005, 2008; Lazarus et al., 2003; Norris \& Conceicão, 2004).

Little is known beyond these demographic trends. One would expect that as people identify themselves through a lens of class that it will, in turn, influence information seeking on various media (e.g., print, television), including online sources. Social class provides an excellent place to look for the role of group-based identity in web-based information seeking. Hence, this study sought to explore whether there is a class-based identity for users and, if it exists, does it influence perceptions of web-based information seeking and finding?

Relationship between class-based and ethnic identities. Despite the way identity is often studied, people rarely operate from a single identity. Instead, as CTI points out, identity is multilayered with identities emerging and receding in their salience (Hecht et al., 2005).

Consequently, it is difficult to know how these identities will be related to each other (Campbell \& Twenge, 2002).

There are many ways to explicate the interrelationship between class and ethnicity. In general, class-based identity has been conceived as primary to ethnic identity, having more influence in individuals' life and ramifications for perceived self-efficacy (Gecas \& Seff, 1990). Among African Americans, studies have shown that class often has more impact on lifestyle and on life in general than ethnicity (Lareau, 2002). Formative research for the current project reached similar conclusions about the role of class-based and ethnic identities in online information seeking (Warren, Kvasny, et al., 2009). Findings from this usability study showed 
that most participants framed their perceptions of online information seeking primarily around their social class. It was only when reflecting back on the experience did these participants recognize the role of their ethnic identities. The qualitative findings were supported by survey data and lead to the conclusion that class-based identity is more salient to online seeking and finding health information than ethnic identity (Warren, 2004). Based on the literature and our prior findings, we hypothesized, that social class predicts the effects of ethnic identity on online information seeking.

Summary. The literature described above suggests that both class and ethnic-based identities, regardless of their causal ordering, play important roles in web use. The question remains, why do these identity factors play such a key role? One possibility, suggested by previous research, is because people respond more positively to online images with which they can identify, those that represent their communal identities, and because people who identify strongly with groups are more likely to seek out websites on which these communal identities are represented. Thus, we hypothesized that for African Americans, ethnic identity would predict perceptions of one's propensity to seek information from websites that include African American culture.

Another possibility is that a lack of and/or distorted representations of one's identities on the web serves to distance the user from the information. These feelings of exclusion, when combined with other exclusionary experiences, might lead members of certain groups to feel that they lack capacity in a web-based world. These feelings of inadequacy are likely to influence searches on the web. In the next section we discuss this phenomenon, which we label "web selfefficacy."

\section{Web Self-Efficacy}


Self-efficacy is the belief individuals have about their capability to perform an action or task to achieve a goal (Bandura, 1993). Efficacy requires a knowledge base to perform behaviors and the belief that the behaviors will have the desired effect (Bandura, 1993). When applied to the web, this construct is defined as the self-perception held by individuals of their ability to interact with the internet and is labeled internet or web self-efficacy (Liaw, 2002; Torkzadeh \& Van Dyke, 2001). Expectations of personal efficacy are thought to be determined by such things as previous experience (e.g., success and failure) and affective state (e.g., self confidence) (Bandura, 1977, 1986). Successes and failures are influential in shaping beliefs toward use of the web and mastery of a particular task (Bandura, 1986). Identities are implicated in all of these factors (Bandura, 1977; Oyserman \& Markus, 1993).

\section{Group-based Identities and Web Self-Efficacy.}

There are a number of reasons to think that self efficacy will play a role in web use by low SES, ethnic minorities. First, we know that, in general, social class affects behavior at least in part through its influence on people's sense of self-efficacy (Bandura, 2002). Education and economic resources influence opportunities to control one's environment, including access to resources. People with access to resources typically feel they have more such control (Gecas \& Seff, 1990). This perception may increase an individual's confidence to achieve particular goals and carry out specific tasks (Bandura, 1993). As a result, socioeconomic status is highly correlated with individuals' confidence and ability to carry out a multitude of tasks, including those related to occupation and education (Ali, McWhirter, \& Chronister, 2005; Campbell \& Twenge, 2002), and we suspect this will extend to online behaviors.

Second, there appears to be an association between ethnic identity and self-efficacy (Aldelman, 1994; Umberson, 1993). Having a more positive or stronger identification with one's 
racial and cultural identities (i.e., ethnic identity) increases one's sense of control and efficacy in handling many life events, such as intercultural communication, racism, and discrimination (Bell \& Nkomo, 1998; Hecht et al., 2003; McCubbin, Thompson, Thompson, \& Futrell, 1998). Thus, it would appear that African Americans who strongly identify with their ethnic group are likely to be more efficacious in dealing with life in general (Sherer et al., 1982) and, again, we reason this should extend to use of the web.

Finally, research on stereotype threat and performance has informed the link between self-efficacy and web use (Jackson et al., 2001b). Stereotype threat is the salience of negative stereotypes about one's identity group in a performance domain (e.g., academic tests, internet use) (Shapiro \& Neuberg, 2007). These threats emerge from both stereotypical representation and/or lack of representation in a particular domain. There is considerable evidence to support the conclusion that stereotype threat among racial and low-income groups is a salient factor hindering beliefs in one's ability to carry out tasks and engage in activities (Oysterman, Fryberg, \& Yoder, 2007; Shapiro \& Neuberg, 2007). Therefore, this notion has been applied to explain self-confidence among African Americans in the domain of internet use (Jackson, et al., 2001). According to Jackson et al. (2001), simply making one aware of their own ethnic and class-based identities through a negative stereotypic association between these group memberships and the ability to use technology effectively can evoke self-doubt and ability to gain mastery in this domain (Jackson et al., 2001). It may also be that websites reflecting either stereotypic communal identities or the absence of these depictions may have an adverse impact on African Americans' confidence and mastery in the domain of seeking and finding identity-relevant information online. 
While it may be that all online information seeking develops web self-efficacy, the sensitivity of self-efficacy to cultural elements such as SES and ethnicity suggests that culturally relevant web-based materials are needed. Thus, we hypothesized that members of underpresented groups may be more likely to maintain a diminished sense of web self-efficacy for mainstream websites and this may explain the relationship between class-based identity and perceptions of the ease in seeking and finding information on the web. This study sought to test whether the relationship between class-based and ethnic identities and web self-efficacy extends to self-perceived web-based information seeking and finding.

\section{Hypotheses and Research Questions}

The review of literature suggests that class-based and ethnic identities may be central to self-perceptions of web-based information seeking and finding. People with certain group-based identities use the web less and/or differently. In addition, the communication of communal identities on the web, which tend to be dominated by mainstream culture in ways that exclude non-mainstream groups and/or distort their identities (Kolko, 2000), may encourage or discourage information seeking. This led us to hypothesize that group-based identities influence perceptions of information seeking and finding on the web. Given recent research, we focused on African Americans, for whom identity appears particularly salient to web-based activities such as information seeking. Based on previous research supporting the primacy of economic-based identities, we hypothesize that social class will predict ethnic identity. In an attempt to explain this effect, we theorized that people who identify with group-based identities would have more web self-efficacy and this would influence their web-based information seeking ability.

Finally, in examining information on the web, two salient processes can be identified: seeking and finding (Napoli, 2001). Some people do not even search for information, often as a 
result of either lack of resources or low efficacy. If resources are provided, there are still issues involved in information seeking - why and how people search. This study addressed the role of identity and efficacy in decisions to seek web-based information. Since African Americans and those occupying a lower socioeconomic status are viewed as using the internet less, it is natural to assume that these identities influence the likelihood of information seeking on the web.

However, seeking does not guarantee finding. Ultimately we were interested in selfperceptions of online effectiveness or the ability to find information. We posited that the processes that lead to seeking ultimately influence perceptions of finding information and predict that seeking information with a feeling of efficacy will positively influence one's perceptions of success in finding information. Based on these observations, the following hypotheses were proposed:

H1: African Americans' class-based identity positively predicts their ethnic identity. H2: African Americans' ethnic identity positively predicts their perceptions of web selfefficacy and propensity to seek information on the web that reflects their communal identity.

H3: African Americans' web self-efficacy and web-based information seeking positively predict perceptions of the likelihood of finding information on the web that reflects their communal identity.

H4: African Americans' web self-efficacy positively predicts their perceptions of the propensity to seek information on the web that reflects their communal identity.

Combining these hypotheses resulted in a path model (see Figure 1) that includes a series of relationships from class-based identity to ethnic identity to web efficacy and information 
seeking then to information finding. This model was the basis for tests of the research hypotheses.

\section{Moderation Effects}

In addition, research has shown that males and females use the web differently (Fallows, 2005) and that African American males and females differ in other aspects of their communication style (Hecht et al., 2003). Nicholson, Grason, and Powe (2003) found that webbased resources are used more by women with a college degree or with a household income of $\$ 50,000$ or more. These researchers also reported that African American women are less likely than European American women to use web-based resources after controlling for other sociodemographic and socio-economic factors. This difference may lie in a lack of web-based ethnically relevant information and/or a preference to seek information from social networks offline (Nicholson, Grason, \& Powe, 2003).

Consistent with the argument above, it is likely that these effects are related to differences in web self-efficacy. In general, men exhibit higher levels of web self-efficacy (Durndell, Haag, Asenova, \& Laithwaite, 2000; Schumacher \& Morahan-Martin, 2000; Torkzadeh \& Van Dyke, 2001). Even as men exhibit higher self-efficacy in using computer technologies, lower relative anxiety toward computers, and greater familiarity with the underlying technology, men and women do not differ significantly in their actual abilities to find various types of information online (Hargittai \& Shafer, 2006). On the other hand, women are much more likely to shortchange themselves when it comes to self-perception of their online skills (Bunz, Curry, \& Voon, 2007). Thus, while women may have comparable information seeking skills their lower web self-efficacy may affect significantly the extent of their web-based 
behavior and the types of uses to which they put the web. As a result, although gender does not appear to affect directly the level of web use, we hypothesized that gender may interact with class-based and ethnic identities in their effects on the other variables in this study. This led us to consider gender as moderator rather than a direct causal variable. We posed the following research question:

RQ1: Does gender moderate the relationships among class-based identity, ethnic identity, web self-efficacy, self-perceived information seeking and finding, specified in the hypothesized model?

Finally, previous experiences with the web also should be important influence on web self-efficacy. Seeing oneself as a "beginner" is likely to influence web-based information seeking (Eastin \& LaRose, 2000). Novice users' lower levels of web self-efficacy may be expressed as higher discomfort and more stress using the web, less satisfaction with their internet skills, uncertainty about how to get started, and the perception that computers are too complicated are nearly as important as cost and lack of access as barriers to getting started on the internet (Eastin \& LaRose, 2000). Web self-efficacy is positively correlated to internet usage, prior internet experience, and outcome expectancies, but negatively correlated with internet stress and self-disparagement (Eastin \& LaRose, 2000). In addition, if fewer African Americans, especially those of lower social class, use the web, then proportionally more of them fall into this usage level (and possibly user-related personal identity) category. Thus, it is important to understand if prior experience interacts with ethnic identity and class-based identity to influence web-based information seeking and finding. We decided to examine this moderation effects and posed the following research question: 
RQ2: Does level of web expertise moderate the relationships among class-based identity, ethnic identity, web self-efficacy, self-perceived information seeking finding, specified in the hypothesized model?

\section{Method}

\section{Sample and Procedure}

Upon approval from the office of research protections, an anonymous pen-and-paper questionnaire was distributed to African American undergraduate and graduate students at a large predominately European American northeastern university and at a predominately African American southeastern university. Eighty-seven percent of the students at the predominately European American northeastern university were European Americans, with only 4\% African American. Recognizing the limitation of generalizability utilizing this student population, African American students also were recruited from a historically black university where 93\% of the students were African American. While no claims are made for the generalizability to all African Americans, the use of these two very different contexts adds to the transportability of the findings.

A total of 279 African Americans participated in this study, 134 (48\%) of whom attended the predominantly European American university and 145 (52\%) of whom attended the predominantly African American university. The sample size is adequate to test the hypotheses (Kline, 2005). Participants' ages ranged from 18 to 43, with an average age of 21.3 years. One hundred seventy-eight participants were women and 101 were men. The median range of the participants' income was reported as $\$ 0-20,000$. It is possible that this distorts downward their actual SES if they are receiving other sources of support (e.g., family, scholarships). Participants 
had been using computers for average of 9.1 years and had been using the internet for average of 7.3 years. The place where the participants used computer most frequently was their home.

Research assistants at the predominantly European American university were trained to conduct survey research and to approach 12 African American student organizations to inquire about data collection. Email advertisements were also sent to these organizations requesting contact information of the organization leader and the location of their office/meetings. The response from these emails and data collection within these organizations was inadequate $(n=51)$ so RAs were instructed to approach individual African American students across the campus (i.e. within various academic departments, football games, hockey games, the student center, on campus grounds, mainstream student groups). At the predominantly African American university students were approached by their instructor to fill out the survey in a basic communication class. Extra credit was not provided. The differences in these sampling methods were necessitated by the available resources and will be discussed later in this paper.

\section{Measures}

The questionnaire asked respondents about their identity and web-based information seeking through mainstream web portals (e.g., Google, Yahoo) and ethnic-based web portals (e.g., BlackAmericaWeb, Africana, and now 'Blackvoices'). They were asked to self-report about their behaviors seeking and findings information on the web that reflects their ethnic and class-based identities. The mean scores, the ranges, and the standard deviations of the above five variables appear in Table 1.

Ethnic identity. The measure of ethnic identity consisted of 5 items derived from the work of Hecht, Larkey, and Johnson (1992) and addressed respondents' ethnic identification (e.g., "Being a member of my racial/ethnic group plays an important part in my life." "Being Black/African American 
is important for how I define myself."), utilizing a seven-point response stem ranging from 1 (strongly disagree) to 7 (strongly agree). Reliabilities of .79 - .95 were reported in the original study (Hecht, Larkey, \& Johnson, 1992). In the current study, coefficient alpha reliability was .87.

Class-based identity. Class-based identity was measured by adapting Hecht et al.'s (1992) ethnic identity items to measure for socioeconomic identity (e.g., "Being a member of a group of people living at my income level plays an important part in my life"; "My socio economic status is central to how I define myself') utilizing a seven-point response stem ranging from 1 (strongly disagree) to 7 (strongly agree). In the current study, coefficient alpha reliability was .86.

Seeking communal information. We were unable to identify a scale to measure people's perceptions of their own propensity to search for information on the web and on websites that reflects their group memberships (i.e., communal identities). As a result, items were developed from the formative research (Warren, 2004) to measure online information seeking that reflects communal identity. Utilizing survey research, 20 African American women were asked an openended question to document what they considered to be representative of their communities online. Standard qualitative data analysis using a compare and contrast method (Lincoln \& Guba, 1985) was utilized to identify patterns across the participants' descriptions. These analyses revealed five categories or themes: Language, Community, Stereotypes, Gender, People Like Me. Participant responses reflecting each of these categories were used to create nine items (see appendix A) that were responded to on a seven-point scale ranging from 1 (strongly disagree) to 7 (strongly agree). Face validity for the items was established by asking two African American females trained in communication research to read and comment on the items. Slight wording revisions resulted. The instrument was pilot tested on 18 African American women $(\alpha=.88)$. 
Next, construct validity was established by in the current study an exploratory factor analysis utilizing Principle Component Analysis as the extracting method and the Direct Oblimin rotation. Two factors were obtained with the eigenvalue of one or greater. Five items were retained in factor 1 at the cut-off point .6 and labeled as a "representation" factor. Another three items belonged to factor 2 and were named the "issue" factor. The factor loadings ranged from .64 to .82 for the items in factor 1 and from .80 to .87 for those in factor 2 . The factor loading of the remaining item was lower than the cut-off point and it was eliminated from the scale. Thus, the remaining 8 items formed the community information seeking scale. The interfactor correlation between the two factors was .46 . The relatively high interfactor correlation suggested that the two factors measured the variable similarly. The Cronbach's alpha of the 8-item version of the scale was .86 , suggesting good internal consistency reliability.

Finding communal information. Since no measure could be located to measure selfperceived finding information on the web and on websites that reflects communal identity, a new measure was developed based on Warren's (2004) formative research using the procedures and themes described above for developing the Seeking Communal Information Scale. Nine items (see appendix B) were developed that were rated on a seven-point scale ranging from 1 (strongly disagree) to 7 (strongly agree). Face validity for the items was established using the same procedures as above. These items was pilot tested as part of the seeking communal information instrument mentioned above on 18 African American women $(\alpha=.88)$.

To establish construct validity in the current study an exploratory factor analysis with the Principle Component Analysis method was conducted. One factor was retained at eigenvalue of one or greater. All nine items were included in the factor. The factor loadings ranged from .63 to .83. The Cronbach's alpha of this scale was .90 , reflecting good internal consistency reliability. 
Web self-efficacy. Self efficacy measure was modified from one developed by Torkzadeh and Van Dyke (2001). Original items included, "I feel confident finding information on the World Wide Web" and "I feel confident browsing the World Wide Web." These items were modified in order to assess how confident the respondents feel in completing information seeking tasks on the web (e.g., "I feel confident that I can find specific information when I look for it on the World Wide Web (WWW)," "I feel confident using websites.") and responded to on a five-point scale ranging from 1 (strongly disagree) to 5 (strongly agree). In the current study, coefficient alpha reliability was .93 .

Internet expertise. This variable was measured by one question (How would you describe your internet expertise?), which was originally rated by a five-point scale (1: barely use internet, 5: expert). In the analyses, this variable was dichotomized at the mean score (3.67) for the model comparison between the relative beginner and the relative expert groups. One hundred and ten participants fell into the beginner group and 169 of them were classified as the expert group.

Results

Since two separate schools were used as data sources, the intra-class correlations for the measures were calculated. These ranged from a low of .02 to a high of .17. Only the ICC for information finding was statistically significant. As a result, we conclude that the dependency of these measures on the sampling unit was not substantial. This issue is further addressed in the analyses below.

\section{Model Fit and Hypotheses Tests}

Because the internal consistency reliabilities of the five variables used in the study were quite high (.86-.93), measurement errors are likely to be small and unlikely to influence the estimation of the model substantially. As a result, path analysis, which tends to produce 
relatively conservative estimations of parameters and fit indices (Hoyle \& Kenny, 1999), was employed to estimate the hypothesized model (Figure 1). For the estimation, we used EQS program utilizing Maximum Likelihood method.

The results of the estimation demonstrated good fit of the model $\left(X^{2}=7.18, d f=4, p=\right.$ $.13 ; N F I=.96 ; C F I=.98 ; R M S E A=.05)$. Thus, the hypothesized model is tenable with the data used in this study. In the estimated model (see Figure 2), class-based identity significantly predicted ethnic identity $(\beta=.33, p<.01)$ and, thus, H1 was supported. Effects of ethnic identity on both web self-efficacy and information seeking were significant $(\beta=.36, p<.01 ; \beta=.16, p<$ .05 respectively) supporting $\mathrm{H} 2$. Both web efficacy and web-based information seeking significantly predicted information finding $(\beta=.11, p<.05 ; \beta=.49, p<.01$ respectively $)$ supporting H3. Effects of web self-efficacy on web-based information seeking were significant $(\beta=-.18, p<.01)$, but negative. Thus, $\mathrm{H} 4$ was not supported.

Post hoc analysis. Because the sample came from two diverse universities and there were implications for social class and sampling methods related to these institutional affiliations, we decided to test the moderation effects of participants' school affiliations on the hypothesized model through a multi-group analysis. A multi-group path analysis allowed us to examine the effects of university affiliation on the relationships within the model. Again, based on Kline (2005), the sample size was adequate for the multi-group analysis given the number of free parameters of the baseline model, which were the same as for the hypothesized model.

With the equality constraints of all six parameters between African American students at a predominantly European American university $(n=134)$ and those at a predominantly African American university $(n=145)$, the analysis produced the following fit indices: $X^{2}=23.14, d f=$ $14, p=.05 ; N F I=.88 ; \mathrm{CFI}=.94 ; R M S E A=.07$. Because malfitting indices indicate an overall 
difference between groups, the above fit indices suggest that there is no clear difference between the models of the students at a European American university and those at an African American university. However, univariate Lagrange Multiplier (LM) showed a significant difference in the parameter from class-based identity to ethnic identity $\left(X^{2}=5.32, p=.02\right)$ between the two school students. This difference was confirmed by the improved model fit indices in another multi-group analysis without the equality constraints of the parameter $\left(X^{2}=18.46, d f=13, p=\right.$ $.14 ; N F I=.90 ; C F I=.97 ; R M S E A=.06)$ and the significant chi-square difference between the analyses with and without the constraint $\left(\Delta X^{2}=5.38, p<.05\right)$. Thus, participants' school affiliations tended to moderate the effect from class-based identity to ethnic identity.

A multiple regression analysis was conducted to check the direction of the moderation effects. Ethnic identity was regressed on class-based identity, school affiliation (European American school = 0; African American school =1), and interaction of class-based identity and school affiliation. The results of this regression analysis appear in Table 2. The significant interaction effect $(\beta=-.42, p<.05)$ reinforced the moderation effects of school affiliations on the parameter from class-based identity to ethnic identity. The negative regression coefficient of the interaction indicated that the effect from class-based identity to ethnic identity were stronger among African American students at predominantly European American school than it was among those at predominantly African American school. Caution must be observed in interpreting these findings due to the fact that different sampling methods were employed at each university. It may be that these methods rather than the schools' racial context are responsible for these differences. 
To check the moderation effects of gender on the model (RQ1), a multi-group analysis between men and women was conducted. The sample was divided into men $(n=101)$ and women $(n=178)$. This sample size tests the limits suggested by Kline (2005) for the smaller group. The hypothesized model (see Figure 1) was used as the baseline model for both men's and women's groups. Both baseline models for men and women were estimated simultaneously with the equality constraints of all six parameters in the model. The analysis produced indices $\left(X^{2}=26.14, d f=14, p=.025 ; N F I=.86 ; C F I=.92 ; R M S E A=.08\right)$ that did not indicate a very good fit and suggested differences in the model between men and women. That is, some of the six parameters specified in the model were different between men and women. This indication of gender differences suggested that gender had moderation effects somewhere in the overall model.

The univariate Lagrange Multiplier (LM) test revealed the specific parameter that resulted in the overall difference. The parameter from ethnic identity to web self-efficacy was significantly different between men and women $\left(X^{2}=9.02, p=.003\right)$. Another multi-group analysis without the equality constraint of this parameter produced the improved model fit indices from the model with the constraint $\left(X^{2}=16.79, d f=13, p=.21 ; N F I=.91 ; C F I=.98\right.$; RMSEA $=.05)$. The significant Chi-square difference between with and without the constraint $\left(\Delta X^{2}=9.35, p<.01\right)$ confirmed that the improvement was significant. Thus, the effect from ethnic identity to web self-efficacy appeared to be moderated most by gender.

A multiple regression analysis was conducted to confirm the moderation effect of gender on the relationship between ethnic identity and web self-efficacy, and to check how it moderated the relationship. In the analysis, web self-efficacy was regressed on ethnic identity, gender (men $=0$; women $=1$ ), and interaction of ethnic identity and gender (see Table 2 for the results of this 
regression analysis). The significant interaction effect of ethnic identity and gender $(\beta=-.89, p<$ .01) reinforced the moderation effect of gender on the relationship between ethnic identity and web self-efficacy. The negative regression coefficient of the interaction effect indicated that the effect of ethnic identity on web self-efficacy is less strong among women than among men.

As for the moderation effects of level of web expertise on the hypothesized model (RQ2), a multi-group analysis with the equality constraints of all six parameters between beginner $(n=$ $110)$ and advanced $(n=169)$ web users suggested the existence of overall difference in the model between the two groups although the difference was less clear than the gender difference $\left(X^{2}=23.12, d f=14, p=.06 ; N F I=.87 ; C F I=.94 ; R M S E A=.07\right)$. A univariate LM test indicated that the significant difference between beginner and advanced web users exists in the parameter from ethnic identity to web self-efficacy $\left(X^{2}=5.98, p=.014\right)$. Another multi-group analysis without the equality constraint of this parameter showed the improved model fit indices including the significant chi-square difference $\left(X^{2}=17.04, d f=13, p=.20 ; N F I=.91 ; C F I=\right.$ $\left..98 ; R M S E A=.05 ; \Delta X^{2}=6.08, p<.05\right)$. Thus, the effect of ethnic identity on web self-efficacy is moderated most by level of web expertise. Additionally, in this analysis, the parameter from web self-efficacy to information seeking appeared to be significantly different between beginner and advanced web users $\left(X^{2}=3.86, p=.05\right)$. The third round of multi-group analysis without the equality constraint of this parameter also produced the significantly improved model fit indices, as well as a significant chi-square difference $\left(X^{2}=13.14, d f=12, p=.36 ; N F I=.93 ; C F I=.99\right.$; $\left.R M S E A=.03 ; \Delta X^{2}=3.90, p<.05\right)$. Therefore, the effect from web self-efficacy to information seeking is another significantly moderated parameter by level of web expertise in the model.

Two multiple regression analyses were conducted to explain this finding. In one analysis, web self-efficacy was regressed on ethnic identity, web expertise, and interaction of ethnic 
identity and level of web expertise (see Table 2 for the results of this regression analysis). The results showed that the interaction effect was significant $(\beta=.66, p<.05)$, confirming the moderation effect of web expertise between ethnic identity and web self-efficacy. The result also indicated that the effect of ethnic identity on web self-efficacy was stronger among advanced web users than among beginner web users. In the other regression analysis, information seeking was regressed on ethnic identity, web self-efficacy, web expertise, and interaction between web self-efficacy and web expertise. The results of this regression analysis are indicated in Table 2 . The interaction effect was not clearly significant but was nearly significant $(\beta=.75, p=.058)$. This result can be interpreted as tentatively supportive evidence for the moderation effect of web expertise on the relationship between web self-efficacy and information seeking. Thus, the effect of web self-efficacy on information seeking is stronger among advanced web users than among beginners.

\section{Discussion}

This study contributes to our understanding of web-based information access by demonstrating the role of identity in self-perceived seeking and finding information. Our findings are based upon individuals' perceptions of web-based information seeking. The use of path analysis afforded an effective means for investigating the relationships among group-based identities, information seeking and finding, and self-efficacy in web use among African American college students. In the test of the overall model, our first three hypotheses were confirmed and showed that class-based and ethnic identities are important predictors of information seeking and web self-efficacy, which, in turn, are significant predictors of the perceived likelihood that information will be found. Web self-efficacy and self-perceived information seeking, however, were negatively related in contradiction to hypothesis 4. Overall, 
these findings add to a growing body of literature suggesting that as an increasingly diverse audience accesses the internet, web-based messages must become more representative of these groups (Appiah, 2003; Hecht et al., 2005).

Our findings demonstrate that one's group-based identity influences perceptions of whether one will seek information on the web that reflects communal identities and the likelihood that information will be found. Online African Americans employ beliefs and concepts originating from their class and ethnic identities to find Web content. A dearth of relevant Web content or content that reproduces stereotypical depictions of African Americans found in print and broadcast media are factors that may limit African Americans' use of the Web (Brock, 2006). In addition, Hoffman, Novak, and Schlosser (2000) argue that the indexing practices of search engines combined with the lower number of Black sites to index may reduce the efficacy of web searches looking for Black cultural content. Even when information is provided, Lazarus and Lipper (2000) found that ethnicity and race affect users' decision to trust information based of the source, the visual style, and tone of online resources. Our findings support arguments (Selwyn, 2003; Stanley, 2003) that the paucity of content may lead people to use the web less frequently or even opt out of web usage entirely because it has no relevance to their lives. Thus, even though online information seeking is likely to be more goal directed than the passive reception of some entertainment formats such as television, identity and identity representations still seem to be salient. It might be informative to compare these more purposive uses of the internet with more entertainment focused searches to see if identity salience diminishes when there is a very specific task at hand, particularly when the task, itself, is highly salient. 
It is significant to note that consistent with our predictions based prior research (Aries \& Seider, 2005; Durant \& Sparrow, 1997; Warren, Kvasny, et al., 2009) class-based identity seems to be more primary than ethnic identity. Although ethnic identity remains an important predictor of online behavior (Appiah, 2003, 2004), class-based identity predicts ethnic identity. In general, socially and economically dominant groups control ownership and production of information technology; hence, these groups may unwittingly promote their own class-based interests (Kvasny, 2006). The strength of these conclusions must be tempered by our cross-sectional methods.

Also consistent with our hypotheses, stronger and more positive identities, both ethnic and class-based, are associated with greater web self-efficacy and self-perceived information seeking. African Americans who more strongly identified with these identities felt confident in their ability to navigate the web and find the information they need. This is consistent with previous research demonstrating that identity is a protective or resiliency factor for African Americans (Collins \& Lightsey, 2001; Hecht et al., 1992). There is a strong correlation between commitment to ethnic identity for African Americans and web self-efficacy.

However, hypothesis 4, predicting a positive relationship between web self-efficacy and self-perceived information seeking, was not confirmed. Although this relationship was significant, its valence was negative indicating that, contrary to predictions, higher efficacy was associated with perceptions of less information seeking. This finding, which held for both males and females as well as for both beginners and more expert users of the web, contradicts expectations based on previous work demonstrating the efficacy beliefs predict intentions and behaviors (Bandura, 1993). At first glance, it appears the web self-efficacy may not operate the same way as efficacy does in other contexts. However, given the positive relationship between 
efficacy and perceptions of finding information, we believe that our respondents with high levels of efficacy may have read the information seeking items as superfluous to their ultimate goal of finding information. That is, they perceived they did not feel the need to seek information because they were very confident of finding it. Past experience may have taught them that when they seek information, they find it. This may be a matter of semantics or it may indicate very different search strategies, with high web self-efficacy users accessing fewer websites in the quest for information. It will be important to determine if such high efficacy levels are actually less functional in this context precisely because they lead to more restricted searches and, as a result, less of the serendipitous findings that characterize many online searches. At the same time, it might be fruitful to explore the role of stereotype threat, which was invoked in justifying the inclusion of self efficacy in the study. Perhaps the relationship between perceptions of selfefficacy and information seeking is moderated by the presence or absence of stereotype threat.

It is interesting to note how participants' school affiliations moderated the relationship between class-based identity and ethnic identity. This relationship was stronger at the European American-dominated institution where African Americans are a small minority. Aries and Seider (2005) note that there may be a heightened awareness of social class where disparities in social class status are more salient as it likely is among African American students attending predominately European American universities.

The first research question asked if gender influenced these relationships. Our findings also demonstrate some gender differences, although the overall model holds quite well for both males and females. The main differences were for the relationship between ethnic identity and efficacy. For males, ethnic identity predicted both web-efficacy and self-perceived information seeking and both predicted self-perceived finding information. For females, ethnic identity 
predicted only efficacy and that, in turn, predicted self-perceived information seeking. In a sense, efficacy fully mediated the relationship between ethnic identity and perceptions of information seeking for females. Overall, the effect of ethnic identity on web self-efficacy is less strong among women than among men. This supports prior research that consistently reports that males as showing a higher degree of web self-efficacy and females exhibiting more computer anxiety, less computer self-efficacy, and less favorable attitude toward computers (Durndell et al., 2000; Jackson et al., 2001a).

Our second research question asked about the effects of web-based expertise on these relationships. The effect of web self-efficacy on self-perceived information seeking is stronger among advanced web users than among beginners. This is logical, since more advanced users are more focused on and immersed in the web itself and may even have developed web-based identity that is more salient than ethnicity in this context. Most studies agree that high exposure to and use of technology is related to a decrease in anxiety and an increase in self-efficacy (Coffin \& MacIntyre, 1999; Igbaria \& Chakrabarti, 1990). We also found that expertise moderated the relationship between ethnic identity and web efficacy. It appears that ethnic identity plays a more significant role among beginners. Contrary to more advanced users who may have created an online identity, beginners appear to be reliant upon the group-based identities to help them make sense of the web during actual seeking information.

\section{Limitations}

As with most studies, there are several limitations to the present dataset and analyses. First, as with most college student samples, one wonders if the findings would replicate with a sample from the general public. The senior author has conducted research with community samples to explore online information seeking by African American women (Warren, 2004; 
Warren, Kvasny, et al., 2009) that served as formative research for the current study. Second, a cross sectional self-report study has inherent limitations in testing a causal model. Future longitudinal studies, including those with experimental designs, are needed to establish causality and refine these conclusions. Third, a more nuanced approach to income is needed to examine the relationships among SES, class identity, and online information seeking. Does SES and class identity interact or does each have an independent effect on information seeking? Are these identities more salient for certain socio-economic classes than for others? Unfortunately, our data did not allow us to answer these questions. Finally, comparative research can contribute to our understanding of identity and online behaviors. We assume other groups, particularly ethnic minorities, share in the desire for representation and that this influences their online information seeking. Until comparative work is conducted, this is only conjecture. We expect that the reader will note additional limitations.

\section{Conclusion}

Seeking to broaden our understanding of internet use among non-dominant groups such as African Americans, this study posited a model that included both class-based and ethnic identities and their possible causal ordering as well as the mediating effects of web self-efficacy and web-based information seeking on perceptions of the ultimate outcome of finding information on the web. This model fit these data well, lending support to our reasoning about the role of group-based and communal identities in self-perceived online information seeking and finding. In order to test this model, the study introduced two new instruments measuring communal identity in seeking information and in finding information, testing the psychometric properties of each. These solid instruments may be useful for other researchers investigating the relationships among communal identities and web use, which this study suggests are related. 
In addition, this study was innovative in its use of the Communication Theory of Identity (CTI), which has previously not been used to conduct an empirical investigation of web use. Most often class-based identity is neglected in examining the use of the web outside of digital divide frameworks. As hypothesized, class-based identity appears to be prior to ethnic identity. While some web producers are creating sites that may be culturally representative of diverse groups to deal with issues of inclusion, this study points out how integral class-based communal membership is in using the web to seek and find information. While cross sectional studies such as this one are not ideal for establishing causal ordering, the findings suggest that future studies investigating culturally appropriate web-based information should be more attentive to classbased identity. Designing virtual resources to address culture may not be as effective as integrating those representations with the target audience's class-based memberships.

We believe that our findings support the conclusion that communicating a diversity of communal identities on the web is integral to both perceptions of web self-efficacy and webbased information seeking and finding. If the web is to achieve its promise as an information source, it must be not only accessible but also relevant across a diverse audience. At present, the web reflects primarily group identities related to mainstream culture (Kolko, 2000). If, as demonstrated in this study, class-based and ethnic identities play a significant role in perceptions of web-based information seeking and the web is not inclusive of these identities, certain groups may not have access to relevant online resources that have revolutionized many aspects of American society, such as those in health care and finance. Hence, a new digital divide may be on the horizon based upon an informational separation. Sound technology policy and practice depend upon a deeper understanding of content and communal membership(s). 


\section{Works Cited}

Adelman, P. K. (1994). Multiple roles and psychological well-being in a national sample of older adults. Journal of Gerontology Social Science, 49, S277-S285.

Agada, J. (1999). Inner-city gatekeepers: An exploratory survey of their information use environment. Journal of the American Society for Information Science, 50(1), 7485.

Airhihenbuwa, C. O. (1995). Health and culture. Thousand Oaks, CA: Sage.

Ali, S. R., McWhirter, E. H., \& Chronister, K. M. (2005). Self-efficacy and vocational outcome expectations for adolescents of lower socioeconomic status: A pilot study. Journal of Career Assessment, 13(1), 40-58.

Anwar, M. A., Majid, S., \& Eisenschitz, T. S. (2000). Information needs and information seeking behavior of agriculture scientists in Malaysia. Library \& Information Science Research, $22(2), 145-163$.

Appiah, O. (2003). Americans online: Differences in surfing and evaluating race-targeted web sites by African American and European American users. Journal of Broadcasting \& Electronic Media, 47(4), 537-555.

Appiah, O. (2004). Effects of ethnic identification on web browsers' attitudes toward and navigational patterns on race-targeted sites. Communication Research, 13(3), 312-337.

Aries, E., \& Seider, M., 2005. The interactive relationship between class identity and the college experience: The case of lower income students. Qualitative Sociology, 28, 419443.

Baker, L. M. (1996). A study of the nature of information needed by women with multiple Sclerosis. Library and Information Science Research, 18, 67-81. 
Bandura, A. (1977). Self-efficacy: Toward a unifying theory of behavioural change. Psychologist, 37, 122-147.

Bandura, A. (1986). Social foundations of thought and action. Englewood Cliffs, NJ: PrenticeHall, Inc.

Bandura, A. (1993). Perceived self-efficacy in cognitive development and functioning. Education Psychologist, 28(2), 117-148.

Bandura, A. (2002). Social cognitive theory in cultural context. Applied Psychology: An International Review, 51(2), 269-290.

Barzilai-Nahon, K., Rafaeli, S., \& Ahituv, N. (2004). Measuring gaps in cyberspace:

Constructing a comprehensive digital divide index. Proceedings from the Conference of Internet Research 5: Workshop on Measuring the Information Society. Brighton, UK.

Bell, E. L., \& Nkomo, S. M. (1998). Armoring: Learning to withstand racial oppression. Journal of Comparative Family Studies, 29, 285-295.

Bolam, B., Murphy, S., \& Gleeson, K. (2004). Individualization and inequalities in health: A qualitative study of class identity and health. Social Science \& Medicine, 59(7), 13551365.

Bottero, W. (2004). Class Identities and the Identity of Class. Sociology, 38, 985-1003.

Brock, A. (2006). A belief in humanity is a belief in colored men: Using culture to span the digital divide. Journal of Computer-Mediated Communication, 11(1).

Bucy, E. P. (2000). Social access to the Internet. Harvard International Journal of Press/Politics, 5(1), 50-61. 
Bunz, U., Curry, C., \& Voon, W. (2007). Perceived versus actual computer-email-web fluency. Computers in Human Behavior, 23(5), 2331-2344.

Campbell, W. K., \& Twenge, J. M. (2002). Self-esteem and socioeconomic status: A metaanalytic review. Personality and Social Psychology Review, 6(1), 59-71.

Coffin, R. J. \& MacIntyre, P. D. (1999). Motivational influences on computer-related affective states. Computers in Human Behavior, 15, 549-569.

Collins, K. W., \& Lightsey, O. R., Jr. (2001). Racial identity, generalized self-efficacy, and selfesteem: A pilot study of a mediation model for African American women. Journal of Black Psychology, 27, 272-287.

Cultural Access Group. 2001. Ethnicity in the electronic age: Looking at the internet through multicultural lens. Access Worldwide Communications. Retrieved November 6, 2006, from http://www.accesscag.com/internet\%20report\%20v.pdf

Deshpande, R., Hoyer, W. D., \& Donthu, N. (1986). The intensity of ethnic affiliation: A study of the sociology of Hispanic consumption. Journal of Consumer Research, 13, 214-220.

Detlefsen, E. G. (2004). Where am I to go? Use of the internet for consumer health information by two vulnerable communities. Library Trends, 53(2), 283-300.

Donthu, N., \& Cherian, J. (1992). Hispanic coupon usage: The impact of strong and weak ethnic identification. Psychology \& Marketing, 9(6), 501-510.

Durant, T. J., \& Sparrow, K. L. (1997). Race and class consciousness among lower- and middleclass African Americans. Journal of African American Studies, 27(3), 334-351.

Durndell, A., Haag, Z., Asenova, D. and Laithwaite, H. (2000). Computer self-efficacy and gender. In E. Balka \& R. Smith (Eds.), Proceedings of the IFIP TC9/WG9.1 Seventh 
international conference on woman, work and computerization: Charting a course to the future (pp. 78-85). The Netherlands: Kluwer.

Eastin, M., \& LaRose, R. (2000). Internet self-efficacy and the psychology of the digital divide. Journal of Computer-Mediated Communication, 6(1).

Fallows, D. (2005). How Women and Men Use the Internet. Pew Internet and American Life Project. Retrieved November 28, 2007, from http://www.pewinternet.org.

Gecas, V., \& Seff, M.A. (1990). Social class and self-esteem: Psychology centrality, compensation, and the relative effects of work and home. Social Psychology Quarterly, $53(2), 165-173$

Gibbons, M. (2005). A historical overview of health disparities and the potential of eHealth solutions. Journal of Medical Internet Research, 7(5), e:50.

Gibbons, M. (2008). eHealth solutions for healthcare disparities. Baltimore, MD: Springer.

Hargittai, E., \& Shafer, S., (2006), Differences in actual and perceived online skills: The role of gender. Social Science Quarterly, 87(2), 432-448.

Haythornthwaite, C. (2007). Social Facilitators and Inhibitors to Online Fluency. Proceedings of the $40^{\text {th }}$ Hawaii International Conference on System Sciences.

Hecht, M. L. (1993). 2002-A research odyssey: Toward the development of a communication theory of identity. Communication Monographs, 60, 76-82.

Hecht, M. L., Jackson II, R. L., \& Ribeau, S. A. (2003). African American communication: Exploring identity and culture. Mahwah, NJ: Lawrence Earlbaum Associates.

Hecht, M. L., \& Krieger, J. K. (2006). The principle of cultural grounding in school-based substance use prevention: The drug resistance strategies project. Journal of Language and Social Psychology, 25, 301-319. 
Hecht, M. L., Larkey, L. K., \& Johnson, J. N. (1992). African American and European American perceptions of problematic issues in interethnic communication effectiveness. Human Communication Research, 19, 209-236.

Hecht, M. L., Warren, J., Jung, J., \& Kreiger, J. (2005). Communication theory of identity. In W. B. Gudykunst (Ed.), Theorizing about intercultural communication (pp. 257-278). Newbury Park, CA: Sage.

Hewstone, M., Rubin, M., \& Willis, H. (2002). Intergroup bias. Annual Review of Psychology, $53,575-604$.

Hoffman, D. L., Novak, T. P. and Schlosser, A. (2000). The evolution of the digital divide: How gaps in internet access may impact electronic commerce. Journal of Computer-Mediated Communication, 5(3).

Hogg, M. A. (1993). Group cohesiveness: A critical review and some new direction. European Review of Social Psychology, 4, 85-111.

Hoyle, R. H., \& Kenny, D. A. (1999). Sample size, reliability, and tests of statistical mediation. In R. H. Hoyle (Ed.), Statistical strategies for small sample research (pp. 195-222). Thousand Oaks, CA: Sage.

Igbaria, M. \& Chakrabarti, A. (1990). Computer anxiety and attitudes towards computer use. Behavior \& Information Technology, 9(3), 229-241.

Jackson, L. A., Barbatsis, G., von Eye, A., Biocca, F., Zhao, Y., \& Fitzgerald, H. (2002). Internet use in low-income families: Implications for the digital divide. IT \& Society, 1(5), 141-165.

Jackson, L. A., Ervin, K. S., Gardner, P. D. \& Schmitt, N. (2001a). Gender and the internet: Women communicating and men searching. Sex Roles: A Journal of Research, 44(5-6), 363-379. 
Jackson, L. A., Ervin, K. S., Gardner, P. D., \& Schmitt, N. (2001b). The racial digital divide: Motivational, affective, and cognitive correlates of internet use. Journal of Applied Social Psychology, 31(10), 2019-2046.

Jackson, L. A., vonEye, A., Barbatsis, G. Biocca, F., Fitzgerald, H., \& Zhao, Y. (2004). The impact of internet use on the other side of the digital divide. Communications of the $A C M, 47(7), 43-47$.

Jameson, A. M., \& Sligo, F.X. (2000). The knowledge- behavior gap in use of health information. Journal of the American Society for Information Science, 51(9), 858-869.

Jeong, W. (2004). Unbreakable ethnic bonds: Information- seeking behavior of Korean graduate students in the United States. Library and Information Science Research, 26(3), 384-400.

Kalichman, S., Weinhardt, L., Benotsch, E., DiFonzo, K., Luke, W. \& Austin, J. (2002). Internet access and internet use for health information among people living with HIV-AIDS. Patient Education and Counseling, 46, 109-116.

Kalyanaraman, S., \& Sundar, S. S. (2006). The psychological appeal of personalized content in web portals: Does customization affect attitudes and behavior. Journal of Communication, 56, 110-132.

Katz, J. E., \& Rice, R. E. (2002). Social consequences of Internet use: Access, involvement, and interaction. Cambridge, MA: The MIT Press.

Kline, R. B. (2005). Principles and practice of structural equation modeling (2nd ed.). New York: Guilford.

Kolko, B. (2000). Race in Cyberspace, New York: Routledge. 
Kvasny, L. (2006). Let the sisters speak: Understanding information technology from the standpoint of the 'other'. The DATA BASE for Advances in Information Systems, 37(4), $13-25$.

Kvasny, L \& Warren, J. (2006). "The representation and performance of menu-driven identities in online health portals." In E. Trauth (Ed.), Encyclopedia of information technology and gender (pp. 745-751). Hershey: Idea Group Publishing.

Lareau, A. (2002). Invisible inequality: Social class and childrearing in black families and white families. American Sociological Review, 67(5), 747-776.

Lazarus, W. \& Lipper, L. (2000). Online content for low-income and underserved Americans: The digital divide's new frontier. Santa Monica, CA: The Children's Partnership.

Lazarus, W., Lipper, L., Roberts, K., Fireman, R., Rose, R. (2003). The search for high-quality online content for low-income and underserved Americans: Evaluating and producing what's needed. Retrieved November 2, 2006, from http://www.childrenspartnership.org/AM/Template.cfm?Section=Reports $1 \&$ Template=/C M/ContentDisplay.cfm\&ContentFileID $=1050$

Liaw, S. S. (2002). Understanding user perceptions of world wide web environments. Journal of Computer Assisted Learning, 18, 137-148.

Lincoln, Y. S., \& Guba, E. G. (1985). Naturalistic Inquiry. New Park, CA: Sage Publications.

McCubbin, H. I., Thompson, E. A., Thompson, A. I., \& Futrell, J. A. (Eds.). (1998). Resiliency in African-American families (Vol. 3). Thousand Oaks, CA: Sage.

Means-Coleman, R. (1998). African American viewers and the African American situation comedy: Situating racial humor. New York, NY: Garland Publishing. 
Media Audit (2007). The Media Audit FYI: Insights for today's changing media and consumer marketplace. Retrieved October 2, 2007, from http://www.themediaaudit.com/aug07_fyi.pdf

Mehra, B., Merkel, C. \& Bishop, A. (2004). The internet for empowerment of minority and marginalized users. New Media and Society, 6(6), 781-82.

Nakamura, L. (2004). Interrogating the digital divide: The political economy of race and commerce in new media. In P. Howard and S. Jones (Eds.), Society online: The internet in context (pp.71-84). Thousand Oaks, CA: Sage Publications.

Napoli, P. M. (2001). Consumer use of medical information from electronic and paper media: A literature review. In R. Rice and J. Katz (Eds.), The internet and health communication: experiences and expectations (pp.79-98). Thousand Oaks, CA: Sage Publications.

Ndiaye, K., Krieger, J. R., Warren, J. R., Hecht, M, \& Okuyemi, K. (2008). Health disparities and discrimination: Three perspectives. Journal of Health Disparities and Research

Nicholson, W., Grason H. \& Powe, N. (2003). The relationship of race to women's use of health information resources. American Journal of Obstetrics and Gynecology, 188, 580-585.

Norris, T. D., \& Conceicão, S. (2004). Narrowing the digital divide in low-income, urban communities. New Directions for Adult and Continuing Education, 101, 69-81.

Okebukola, P.A., Sumampouw, W. \& Jegede, O.J. (1992). The experience factor in computer anxiety and interest. Journal Educational Technology Systems, 20(3), 221-229.

Oyserman, D., Fryberg, S. A., \& Yoder, N. (2007). Identity-based motivation and health. Journal of Personality and Social Psychology, 93(6), 1011-1027. 
Oyserman, D., \& Markus, H. R. (1993). The sociocultural self. In J. Suls (Ed.), Psychological perspectives on the self (pp. 187-220). Hillsdale, New Jersey: Lawrence Erlbaum Associates.

Pew Internet and American Life (2007). Demographics of internet users, Washington DC: Pew Internet and American Life Project. Retrieved October 2, 2007, from http://www.pewinternet.org/trends/User_Demo_6.15.07.htm

Schumacher, P., \& Morahan-Martin, J. (2000). Gender, internet and computer attitudes and experiences. Computers in Human Behavior, 16, 13-29.

Selwyn, N. (2003). Apart from technology: understanding people's non-use of information and communication technologies in everyday life. Technology in Society, 25. 99-116

Shapiro, J. R., \& Neuberg, S. L. (2007). From stereotype threat to stereotype threats:

Implications of a multi-threat framework for causes, moderators, mediators, consequences, and interventions. Personality and Social Psychology Review, 11(2), 107-130.

Shepard, C., Giles, H., \& Le Poire, B. A. (2001). Communication accommodation theory. In W. P. Robinson \& H. Giles (Eds.), The new handbook of language and social psychology (pp. 33-56). New York: John Wiley.

Sherer, M., Maddux, J., Mel-Caclante, B., Prentice-Dunn, S., Jacobs, B., \& Rogers, R. W. (1982). The self-efficacy scale: Construction and validation. Psychobiological Reports, $51,663-671$

Spink, A. \& Cole, C. (2001). Information and poverty: Information-seeking channels used by African American low-income households. Library \& information Science Research, 23, 45-65.

Stanley, L. (2003). Beyond Access: Psychosocial barriers to computer literacy. The Information Society, 19, 407-416. 
Tajfel, H., \& Turner, J. C. (1986). The social identity theory of intergroup behavior. In S. Worchel \& W. G. Austin (Eds.), Psychology of intergroup relations (pp. 7-24). Chicago, IL: Nelson-Hall.

Torkzadeh, G., \& Van Dyke, T. P. (2001). Development and validation of an internet selfefficacy scale. Behavior and Information Technology, 20(4), 275-280.

Umberson, D. (1993). Sociodemographic position, worldviews, and psychological distress. Social Science Quarterly, 74(3), 575-589.

Van Dijk, J. \& Hacker, K. (2003). The digital divide as a complex and dynamic phenomenon. The Information Society, 19, 315-326.

Vishwanath, A. (2007). Information search efficacy: A new measure and its initial tests. Communication Research Reports, 24(3), 195-203.

Warren, J. R. (2004) Black Women and Online Health Information Seeking. Paper presented at the meeting of the National Communication Association, Chicago, IL.

Warren, J. R., Allen, M., Okuyemi, K. Kvasny, L., \& Hecht, M. L. (2009). Targeting single parents in preadolescent substance use prevention: Internet characteristics and information relevance. Drugs: Education, Prevention and Policy.

Warren, J. R., Kvasny, L., Hecht, M. L., Ahluwalia, J. S., \& Okuyemi, K. S. (2009). Barriers, control and identity in health information seeking: Listening to lower income African American women. Manuscript submitted for publication. 


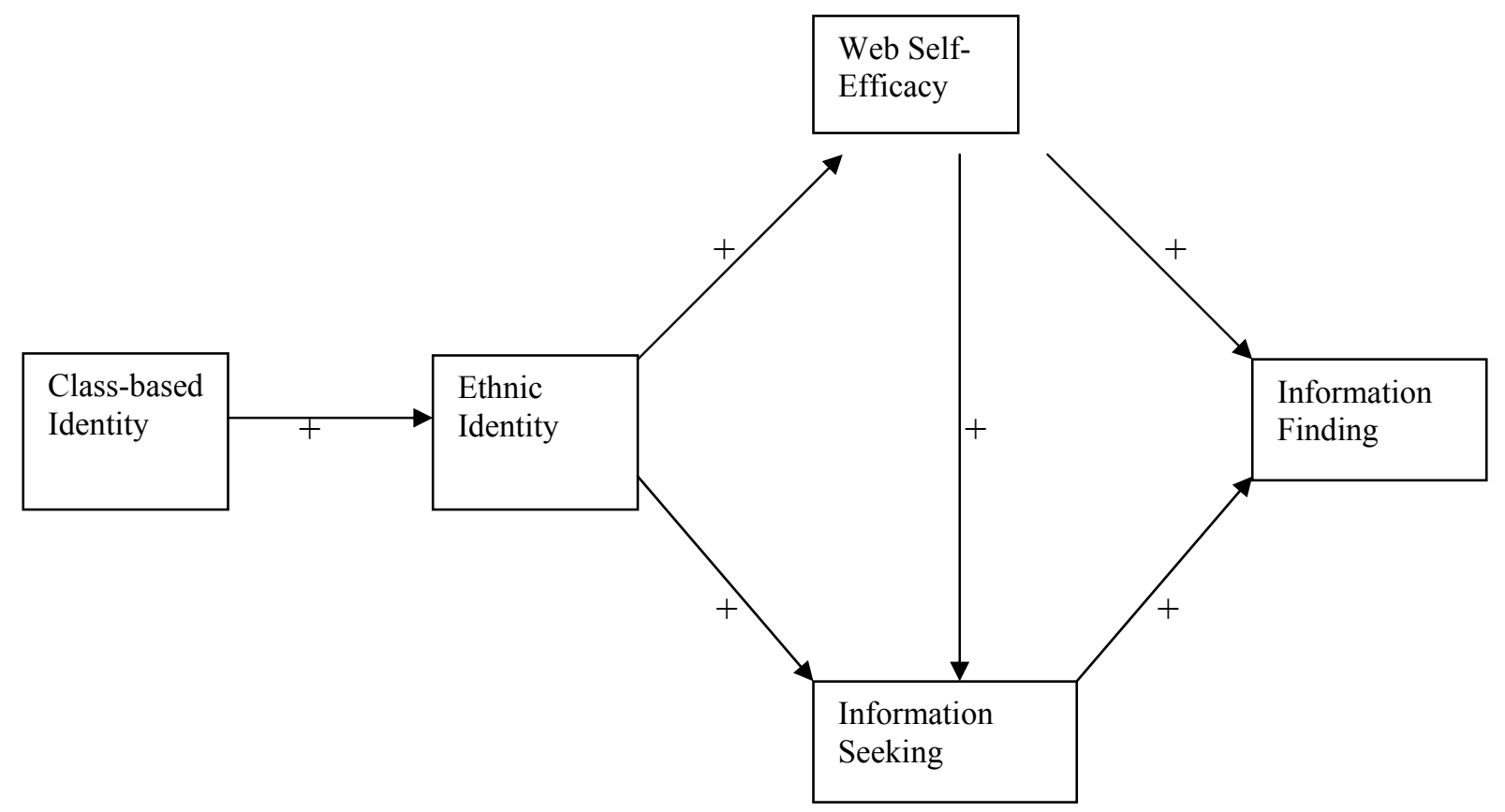

Figure 1. Hypothesized Model 
Table1. Means and Standard Deviations

\begin{tabular}{lcccc}
\hline & Minimum & Maximum & Mean & SD \\
\hline Class-Based Identity & 1 & 7 & 4.15 & 1.51 \\
Ethnic Identity & 1 & 7 & 5.79 & 1.22 \\
Internet Self-Efficacy & 1 & 5 & 4.25 & .76 \\
Seeking Communal Information & 1 & 7 & 3.90 & 1.32 \\
Finding Communal Information & 1 & 7 & 4.42 & 1.26 \\
Internet Expertise & 1 & 5 & 3.67 & .76 \\
\hline
\end{tabular}


Table 2. Results of Regression Analyses for Interaction Effects

Dependent Variable: Ethnic Identity

\begin{tabular}{|c|c|c|}
\hline & $\beta$ & $p$-value \\
\hline Social Class Identity & .48 & .000 \\
\hline School Affiliation & .46 & .006 \\
\hline Social Class Identity x School Affiliation & -.42 & .019 \\
\hline \multicolumn{3}{|c|}{ Dependent Variable: Web Self-Efficacy } \\
\hline & $\beta$ & $p$-value \\
\hline Ethnic Identity & .63 & .000 \\
\hline Gender & .87 & .003 \\
\hline Ethnic Identity x Gender & -.89 & .003 \\
\hline
\end{tabular}

Dependent Variable: Web Self-Efficacy

\begin{tabular}{lcc} 
& $\beta$ & $p$-value \\
Ethnic Identity & .20 & .023 \\
Web Expertise & -.59 & .030 \\
Ethnic Identity x Web Expertise & .66 & .020 \\
\hline
\end{tabular}

Dependent Variable: Information Seeking

\begin{tabular}{lcc} 
& $\beta$ & $p$-value \\
Ethnic Identity & -16 & .015 \\
Web Self-Efficacy & -.38 & .002 \\
Web Expertise & -.69 & .067 \\
Web Expertise x Web Self-Efficacy & .75 & .058 \\
\hline
\end{tabular}




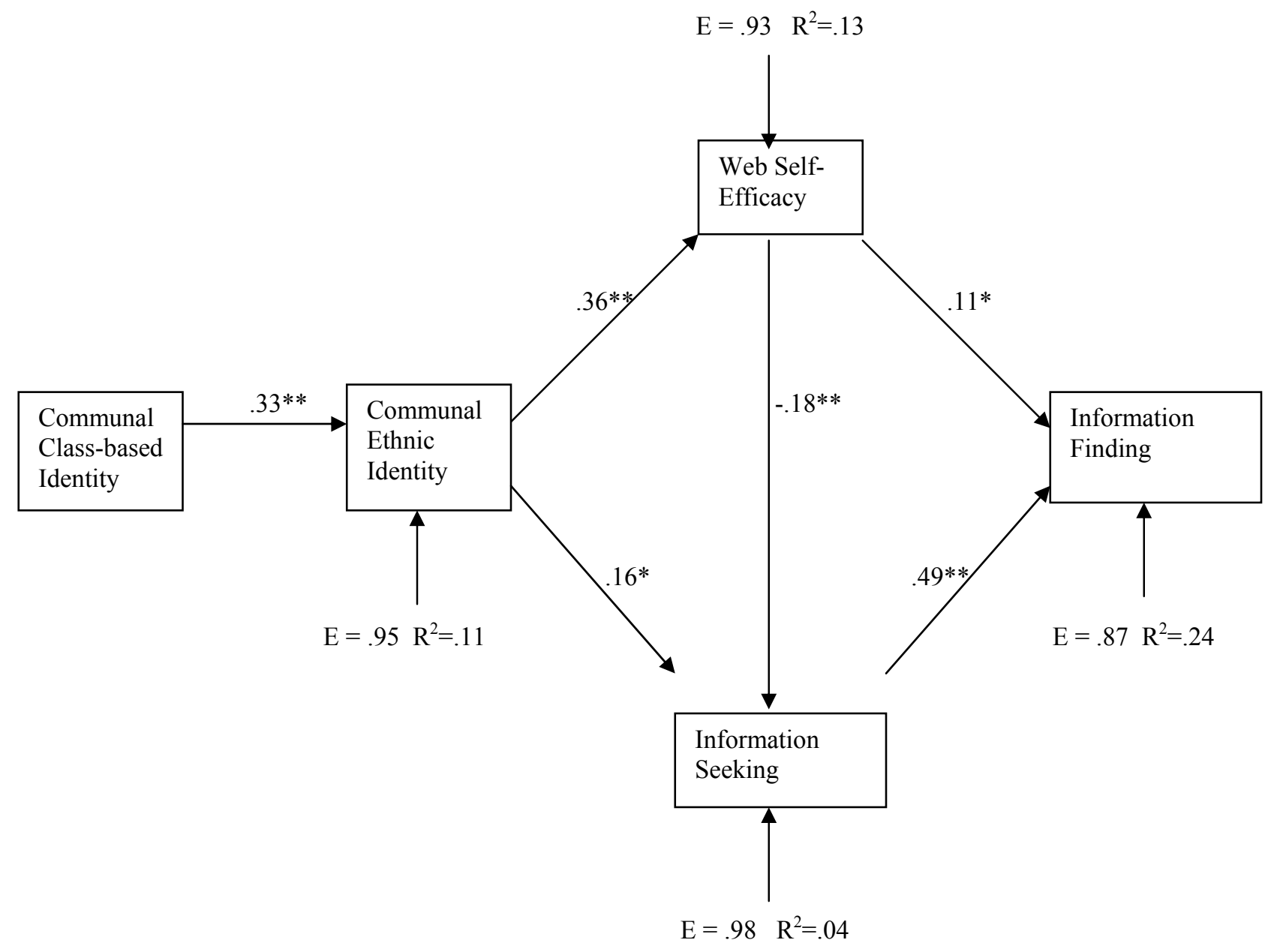

Figure 2. Estimated Model

Note. ${ }^{*}=p<.05 ; * *=p<.01$

\section{Notes}

${ }^{1}$ An estimation of a model using a latent variable approach usually produces magnified path coefficients and, thus, better fitting indices, compared to those from a path analysis (Hoyle \& Kenny, 1999). Thus, when an estimation of a model by a path analysis shows all significant path coefficients and good fit of the model, there is no substantial difference in the status of the model 
fit and the significance of path coefficients between an estimation of a model by a path analysis and that based on a latent variable approach. 


\section{Appendix A. Seeking Communal Information}

1. I search for web information that uses the language of my community.

2. I search for websites that represent my community.

3. I search for websites with pictures of people who look like me.

4. I look for websites that have words and phrases used in my community.

5. I search for sites that express issues in my community.

*6. I search for sites free from stereotypes about my community.

7. I search for sites that discuss women/men issues.

8. I search for sites that show activities that go on in my community.

9. I search for websites where some of the picture look like (body shape, dress, etc.) people in my community.

Note. The asterisked item is eliminated in the analyses. 
Appendix B. Finding Communal Information

1. I found web information that uses the language of my community.

2. I located websites that represent my community.

3. I discovered websites with pictures of people who look like me.

4. I found websites that have words and phrases used in my community.

5. I located sites that express issues in my community.

6. I found sites free from stereotypes about my community.

7. I found sites that discuss women/men issues.

8. I found sites that showed activities that go on in my community.

9. I discovered websites where some of the pictures look like (body shape, dress, etc,) people in my community. 